University of Nebraska - Lincoln

DigitalCommons@University of Nebraska - Lincoln

Faculty Publications: Department of

Entomology

Entomology, Department of

2006

Effects of Temperature on Development of Phormia regina

(Diptera: Calliphoridae) and Use of Developmental Data in

Determining Time Intervals in Forensic Entomology

\author{
P. D. Nabity \\ University of Nebraska-Lincoln \\ Leon G. Higley \\ University of Nebraska-Lincoln, Ihigley1@unl.edu \\ Tiffany M. Heng-Moss \\ University of Nebraska-Lincoln, thengmoss2@unl.edu
}

Follow this and additional works at: https://digitalcommons.unl.edu/entomologyfacpub

Part of the Entomology Commons

Nabity, P. D.; Higley, Leon G.; and Heng-Moss, Tiffany M., "Effects of Temperature on Development of Phormia regina (Diptera: Calliphoridae) and Use of Developmental Data in Determining Time Intervals in Forensic Entomology" (2006). Faculty Publications: Department of Entomology. 277.

https://digitalcommons.unl.edu/entomologyfacpub/277

This Article is brought to you for free and open access by the Entomology, Department of at DigitalCommons@University of Nebraska - Lincoln. It has been accepted for inclusion in Faculty Publications: Department of Entomology by an authorized administrator of DigitalCommons@University of Nebraska - Lincoln. 


\title{
Effects of Temperature on Development of Phormia regina (Diptera: Calliphoridae) and Use of Developmental Data in Determining Time Intervals in Forensic Entomology
}

\author{
P. D. NABITY, L. G. HIGLEY, ${ }^{1}$ AND T. M. HENG-MOSS \\ Department of Entomology, 202 Plant Industry, University of Nebraska, Lincoln, NE 68583-0816
}

J. Med. Entomol. 43(6): 1276-1286 (2006)

\begin{abstract}
Precise developmental data for forensic indicator blow fly species are essential for accuracy in the estimate of the post-mortem interval (PMI). Why, then, does the determination of the PMI result in conflicting time frames when published conspecific developmental data are used? To answer this question, we conducted constant temperature trials between the developmental minimum temperature and upper threshold temperatures $\left(8-32^{\circ} \mathrm{C}\right)$ on the forensically important blow fly species Phormia regina (Meigen) (Diptera: Calliphoridae). Flies were reared using two designs to quantify sources of variation. We measured rearing container temperatures and internal growth chamber temperatures by using thermocouples to accurately record temperatures experienced by larvae and to construct a degree-day model. Differences in experimental design, as seen across temperature studies for this fly species, did not significantly impact larval development. We also found that using set chamber temperatures rather than rearing container temperatures altered the final degree-day model. Using any minimum threshold (including an empirically determined true minimum) other than that from linear interpolation (x-intercept) violated degree-day assumptions and invalidated estimates of the PMI. We observed the minimum developmental temperature to be higher $\left(14^{\circ} \mathrm{C}\right)$ than that generated under the $\mathrm{x}$-intercept method $\left(5.46^{\circ} \mathrm{C}\right)$ by using data from oviposition to adult emergence. This difference along with the noted difference in accumulated degree-days (using different base temperatures) suggests a need for additional experimentation on other forensically important fly species at low temperature thresholds to help with development of curvilinear models. Former and current estimates of the PMI may be inaccurate if the process to determine the time frame ignored degree-day model assumptions or was based upon questionable data sets.
\end{abstract}

KEY WORDS blow flies, degree-day analysis, temperature thresholds, post-mortem interval

Forensic entomology is growing with the application of new technologies and the availability of new data on forensically important species. Arguably, the key contribution of entomological information in criminal investigations is in the determination of the post-mortem interval (PMI). Successional patterns of insect invasion may provide PMI indications over longer time intervals. For shorter periods, however, developmental rates of larvae are used. Decomposers such as blow flies typically arrive and oviposit minutes after death. When correlated with environmental temperatures, development of these carrion flies can provide a method for estimating the PMI. Consequently, precise developmental data for forensic indicator species are essential for accuracy in the PMI estimate. Many calliphorid and sarcophagid species have been studied because of their prolific occurrence on cadavers, economic importance, or role in decomposition succession (Byrd and Butler 1996, 1997, 1998; Anderson 2000;

\footnotetext{
${ }^{1}$ Corresponding author, e-mail: lhigleyl@unl.edu.
}

Byrd and Allen 2001; Grassberger and Reiter 2001, 2002a,b; Grassberger et al. 2003).

To use larval development in estimating PMI, accurate information on the development of individual species is essential. Currently, much of the available information comes from relatively few studies, often with limited data sets (Byrd and Allen 2001, Higley and Haskell 2001). For example, data sets developed within limited temperature ranges (especially at low temperatures) (Nabity 2005) and data sets with only single measures (no replication) exist for some temperatures. Byrd and Butler (1996, 1997, 1998) produced data sets by using cyclic temperatures spanning the median temperatures of the developmental spectrum $\left(15.6-32.2^{\circ} \mathrm{C}\right.$ in $5.5^{\circ} \mathrm{C}$ intervals); and, Byrd and Allen (2001) evaluated a greater temperature range $\left(10-40^{\circ} \mathrm{C}\right)$. However, neither study evaluated growth rates near the developmental threshold. Similarly, Greenberg (1991) evaluated broad temperature ranges but produced data sets without regard for the minimum threshold and published data based upon single measures. Developmental minima and maxima 
are not established for many forensic species, and developmental requirements, such as degree-days, usually are not explicitly determined. More comprehensive data are emerging for some species (e.g., Byrd and Allen 2001, Grassberger et al. 2003), but there remains a clear need for additional in-depth data on development of forensically important insect species, such as Phormia regina (Meigen) (Diptera: Calliphoridae).

A further need is estimation of variation for constructing the PMI. One important issue is the assumption that oviposition occurs shortly after death; yet, various circumstances (such as diurnal versus nocturnal oviposition patterns, access to a body, or cold temperatures) may delay oviposition. Another major source of variation comes in determination of developmental periods. Greenberg (1991), Byrd and Allen (2001), and Clarkson et al. (2004) found fluctuating temperatures delayed larval development compared with constant temperature rearing. Thus, studies using only cyclic temperatures to test development for some fly species are incomplete. For example, Byrd and Butler (1996, 1997, 1998) tested development only under cycling temperatures with a period of $5.5^{\circ} \mathrm{C}$, and one constant temperature $\left(25^{\circ} \mathrm{C}\right)$. They argued for the fluctuating temperatures because specimens in nature are subject to fluctuating, not constant, temperatures. These studies also evaluated fly development under various photoperiod settings; a concept that has not been directly tested in the literature. Although there are data to suggest photoperiod may influence development (unpublished data) and investigators have shown dipteran behavior to be augmented by light (e.g., Grassberger and Reiter 2001, 2002a,b), there are no conclusive studies testing the influence of light on blow fly development.

Another important issue in determining developmental periods is that of accurate temperature measurement. Insect developmental rate increases linearly, but only between the temperature extremes; developmental rate becomes curvilinear at both high and low extremes with increases or decreases in temperature. Within the nonlinear portions of the temperature development association, equal deviations from mean temperature (abscissa) result in unequal deviations in developmental time (ordinate). This is known as the rate summation effect, and it alters the interpretation of data near thresholds when generated under fluctuating temperatures (Kaufmann 1932). Because most environmental factors slow rather than increase development, with the exception of certain chemicals in the substrate (e.g., cocaine, Goff et al. 1989), it is important to have the fastest developmental time when calculating the PMI. Thus, studies conducted under nonconstant temperature regimes assume a conservative developmental time, because larval developmental rate is slower (based upon studies) along the linear portion and either faster than expected (at low temperatures) or slower than expected (at high temperatures) within the curvilinear or threshold portions (because of rate summation).
Designs by Byrd and Butler (1996, 1997) also replicated larval containers within a chamber, rather than between chambers. Grouping all rearing cups under the same environmental temperature, whether constant or cyclic, may obscure the actual thermal environment insects experience because of within chamber temperature variation. Additionally, there is little if any mention of variability occurring in temperature studies, and only recently have investigators placed electronic checks (thermocouples and data loggers) within experiments to monitor temperatures (Anderson 2000, Clarkson et al. 2004). Chamber effects may create the variation observed in data sets within and between studies on the same species (Kamal 1958, Greenberg 1991, Byrd and Allen 2001), and this variation needs to be investigated.

Traditionally, the experimental unit is defined as the entity to which a treatment is applied. However, in growth chamber studies involving temperature, the treatment is not evenly applied (all locations within the chamber do not experience the same temperature), and the presumed temperature (the set-chamber temperature) may not match internal chamber temperatures. Thus, some investigators and statisticians have argued that within-chamber replications are permissible if the treatments are recorded for each within chamber "replicate." This argument assumes that temperature is the only significant factor affecting replicates; otherwise, between-chamber replications (to account for example, variability in light and relative humidity) would be necessary. The opposite interpretation is that within chamber replicates, where temperature is the treatment, represent a lack of, or pseudoreplication (Hurlbert 1984).

A less appreciated issue in the design of temperature studies is randomization. Typically, to compare a number of temperature treatments, a complete set of treatments would be randomized across chambers. Alternatively, a single treatment (temperature) may be applied to multiple chambers, with different treatments being tested through time. In this second design, the study is replicated, but because there could be an influence of time, the study is "pseudorandomized" (assignment of treatments is not random through time).

A final point involves the goal of studies whose purpose is to determine a quantitative biological response to temperature, such as determining temperature-growth rate relationship. When determining a mathematical relationship, regression, not treatment comparison, is of utmost importance. From this perspective, certain types of pseudoreplication and pseudorandomization should be permissible. Unfortunately, failure to properly assess treatment (e.g., measure exact temperature insects experience in a chamber) and failure to avoid bias (through use of single chamber, pseudorandomization, and similar problems) may invalidate the points generated for regression. Finally, because regression relationships are highly dependent on the spread and range of values tested, clustered points (through the selection of many temperatures in a narrow range and few 
outside this range) can distort or obscure the actual relationship.

Because P. regina is well studied in the literature, frequently associated with death scenes, and serves as a primary specimen used to construct PMI, additional investigation of the temperature-developmental time relationship is merited. P. regina is a forensically important blow fly common to Holarctic regions and distributed in North America north of Mexico City. It is abundant in the spring and fall when cooler temperatures are prevalent and in higher altitudes of warmer areas (Hall 1948). P. regina readily visits decomposing material and frequents cadavers at crime scenes. Kamal (1958), Greenberg (1991), Anderson (2000), and Byrd and Allen (2001) looked at developmental rates of $P$. regina, but they did not examine potential sources of variation within their experiments.

The focus of this study was to gather additional data on $P$. regina developmental rates, especially on the developmental minimum temperature threshold, and to determine an accurate low temperature measurement. We selected two experimental designs, emulating designs used on other forensically important fly species. Our first objective was to test whether key environmental factors (e.g., photoperiod and substrate) interacted in ways that altered larval developmental time. We also examined how measures of stage transition (by mode or first 10\%) altered estimates of developmental time. Our second objective was to determine whether experimental bias occurred by using temperatures set for growth chambers (hereafter setchamber temperatures) rather than those measured within the rearing containers (hereafter rearing-container temperatures). Our third objective was to compare estimates based on the $\mathrm{x}$-intercept versus an observed minimum developmental threshold. Finally, we examined the effects of any differences on the final degree-day model, because it is used in estimating the PMI.

\section{Materials and Methods}

Flies for our experiments were collected on University of Nebraska East Campus in Lancaster County, $\mathrm{NE}\left(40^{\circ} 85^{\prime}, 96^{\circ} 75^{\prime}\right)$ by using baited traps $(2000-$ 2004). Initially, traps were baited with liver, although additional traps in 2000 were baited with rotten bananas, mango, pears, and other noncitrus fruits (beer was added to increase fermentation). P. regina were identified, separated, and placed in fine wire mesh cages (30-cm [length by width by height] cubes) in laboratory growth chambers (models E-30B, I-35L, LLVL, VLX, Percival Scientific, Perry, IA). A continual colony survived on water, sugar, and a mixture of powdered egg whites and powdered milk. We set colony temperatures from 20 to $25^{\circ} \mathrm{C}$ and assigned a photoperiod of 16:8 (L:D) h for colonies used for the first experiments (in 2001) and 24:0 (L:D) h for colonies used in the second experiment (2004). The photoperiod used for rearing was used for the experiments that year. Relative humidity varied with season from 50 to $70 \%$. Eggs were collected after oviposition on liver or hamburger (ground beef) substrate. We used egg masses no older than $6 \mathrm{~h}$ for experiments. Experiments began using flies from the eighth and third generations for 2000 and 2004, respectively. We used emerged flies to restock the colonies.

We examined fly development by using two different designs to see whether bias occurred. The first series of experiments began in August 2000 and ended in August 2001. The second series began in August 2003 and ended in December 2004. Experimental designs differed between study years. The first experiment used one rearing container within one growth chamber; so, the experimental unit was the environmental growth chamber. We tested seven temperatures replicating chambers set at 32 and $26^{\circ} \mathrm{C}$ four times, $20,14,10$, and $8^{\circ} \mathrm{C}$ twice; and $12^{\circ} \mathrm{C}$ once. In the second design the experimental unit was the chamber but with each temperature treatment replicated at the same time across four chambers. The second series followed a completely randomized design when assigning rearing containers to environmental growth chambers. We tested five temperatures $(12,15,20,25$, and $30^{\circ} \mathrm{C}$ ) replicating each temperature over four chambers and with three subsamples (rearing containers) per chamber. Preliminary studies showed a horizontal gradient from left to right inside the chamber, with significantly increased temperatures in the end container relative to the middle container, because of proximity to lights. Therefore, container placement was randomized when multiple subsamples occurred within chamber.

In addition the experimental setups evaluated different diets, photoperiods, and stage transition times. We used two rearing substrates and diet media. In 2001 , larvae developed on $80 \%$ lean ground beef chuck (hereafter meat) enclosed in foil pouches in sandlined 2-liter containers. In 2004, larvae developed on beef liver enclosed in foil pouches in 3.55-liter containers lined with medium-grade vermiculite. All containers were vented to allow for gas exchange. For photoperiod, in 2001 larvae developed under 16:8 (L:D) h; in 2004, larvae developed under 24:0 (L:D) h. For population stage transition, we measured pupal and adult stage transition times under different criteria. In 2001, we used modal developmental time. In 2004, we used the fastest developmental time (typically $\leq 10 \%$ of the population)

We used the same methods of recording temperatures and calculating degree-days for both experiments. We checked all chambers in 12-h intervals to verify chamber function and to determine developmental stage. We used thermocouples (TMC6-HB, with $0-44^{\circ} \mathrm{C}$ range, $\pm 0.4^{\circ} \mathrm{C}$ accuracy at $20^{\circ} \mathrm{C}$, and $0.2^{\circ} \mathrm{C}$ resolution, and $\mathrm{TMCx}-\mathrm{HD}$, with -40 to $50^{\circ} \mathrm{C}$ range, $\pm 0.5^{\circ} \mathrm{C}$ accuracy at $20^{\circ} \mathrm{C}$, and $0.41^{\circ} \mathrm{C}$ resolution) from a Hobo H8 outdoor/industrial four-channel external logger (Onset Computer Corp., Pocasset, MA) to record internal chamber and container temperatures. One thermocouple was placed within rearing containers to measure overall rearing container temperature and account for any metabolic heat generated. 
Thus, three thermocouples recorded internal chamber temperatures in 2001, and one thermocouple recorded chamber temperature in 2004. Temperatures were recorded every $15 \mathrm{~min}$ to the nearest $0.1^{\circ} \mathrm{C}$.

In a pseudoreplicated (one-chamber) pilot study in 2004 , we randomly assigned an egg cluster (of ages $\leq 6$ and $\leq 3 \mathrm{~h}$ old at $25^{\circ} \mathrm{C}, 0.5 \mathrm{ADD}_{12}$ were $\leq 78$ and 39 , respectively) to 16 opaque Dixie cups. We then fitted three cups and the internal chamber with thermocouples and placed the setup in a growth chamber set to $11^{\circ} \mathrm{C}$. Larval hatch was monitored to note occurrence, and no developmental times were recorded.

The developmental minima, maxima, and thermal constants were determined to ensure that degree-day models were based solely on the linear portion of the developmental curve. Commonly, these values are determined by regressing 1 / developmental time versus temperature and by using the intercept of this regression as a base temperature for calculating the thermal constant. Because using the inverse of developmental time skews the variance structure, this approach underestimates low temperature curvilinearity, which can underestimate the slope of the actual linear portion of the developmental curve. The number of data points and the range of temperatures examined also can influence the slope of the developmental curve. Although no single procedure (short of having sufficient experimental points for a curvilinear [sigmoidal] regression) can eliminate these problems, we used a multiple step procedure to address these issues.

First, we identified the linear portion of the developmental curve by iteratively checking for nonlinearity in the lower and upper portions of the developmental curve. Specifically, for regressions of developmental time in days versus temperature and of 1 / $d$ versus temperature we 1 ) used a runs test (a statistical measure of unidirectional error, or nonrandomness) to identify significant nonlinearity in the regression (GraphPad Prism 4 software, GraphPad Software Inc., San Diego, CA), 2) examined $R^{2}$ values and patterns of residuals from regressions (GraphPad Software Inc.), and 3) looked at 95\% prediction bands (indicating where $95 \%$ of data points fall between) for observed data points in the 1 /d versus temperature regression. We used $95 \%$ prediction bands as opposed to $95 \%$ confidence intervals, which result in many points outside the bands, because the $95 \%$ confidence interval is a measure of the true mean or relationship, not a prediction of where points should be. Based on these criteria, we sequentially eliminated low and upper temperature points until the runs test was nonsignificant, the $R^{2}$ showed no improvement, residuals showed a random distribution, and experimental points were within $95 \%$ prediction bands of the regression.

Second, we determined the developmental minimum from the $\mathrm{x}$-intercept from a linear regression; once the appropriate temperature range was established, we regressed 1/developmental time versus temperature to determine the appropriate developmental minimum.
Third, we calculated the thermal constant (accumulated degree-days; ADD) for the biological period of interest (here, development from egg to adult). For each treatment temperature, this was (temperature minimum) $\times$ developmental time.

Fourth, we confirmed that the calculated thermal constants are independent of temperature. The slope of the linear regression of thermal constants versus temperature was tested to determine whether it was significantly different from zero.

Finally, we determined the thermal constant either by slope of the thermal constant versus temperature regression or the mean of the thermal constant across measured temperatures. These values should be approximately equal, and there is no a priori reason to choose one method over the other. However, because most literature values of thermal constants are based on means, we also used the mean for comparison.

Because temperature recordings were made every $15 \mathrm{~min}$, we calculated daily degree-days as the sum of these 15-min intervals over a day. Some variation in temperature occurred in chambers associated with normal chamber temperature regulation (the compressor turning on and off) and fluctuations associated with daily monitoring of larvae (typically this occurred over $<5 \mathrm{~min}$ ). In four chambers of the first experiment series, we noted temperatures were routinely higher during photophase than during scotophase.

Data Analysis. For comparisons between measures of temperature (rearing-container temperatures versus set-chamber temperatures), we analyzed data recorded by thermocouples corresponding to their placement in the environmental growth chamber. We averaged thermocouples by temperature treatment $\left(30^{\circ} \mathrm{C}, 25^{\circ} \mathrm{C}\right.$, and so on) to determine within chamber temperature variation and compared internal chamber temperatures to assess between chamber variations. We compared developmental time under setchamber and rearing-container temperatures by using an analysis of covariance (ANCOVA) with temperature covariate at a significance level $P \leq 0.05$ (PROC MIXED, SAS Institute 2002).

For comparisons between designs we used metaanalysis, a statistical analysis integrating the results of multiple studies (e.g., Hedges and Olkin 1985), because the studies occurred at two time periods. We compared developmental times to pupation and adult emergence under the same parameters for comparisons of temperature measures. We also correlated averaged container temperature to observed stage transition times to generate averaged development data for P. regina (Table 1).

For calculations of accumulated degree-days, we used the regressed $\mathrm{x}$-intercept as the base temperature. This temperature was determined from regression of data within the linear range according to the methods outlined above (by using the runs test in combination with the residual plots generated under the regression (GraphPad Software Inc.). ADD values from egg to adult emergence are denoted as ${ }^{\mathrm{e}-\mathrm{a}} \mathrm{ADD}_{\mathrm{x} \text {-int}}$, and $\mathrm{ADD}$ from egg to pupation are de- 
Table 1. Mean $\pm \mathrm{SE}$ developmental time to pupation and adult emergence by temperature for both 2001 and 2004 experiments

\begin{tabular}{cccccc}
\hline \hline \multirow{2}{*}{ Yr } & \multicolumn{2}{c}{ Temp $\left({ }^{\circ} \mathrm{C}\right)$} & & $\begin{array}{c}\text { Egg to } \\
\text { pupation }^{a}(\mathrm{~d})\end{array}$ & $\begin{array}{c}\text { Egg to } \\
\text { adult }^{a}(\mathrm{~d})\end{array}$ \\
\cline { 2 - 4 } 2001 & Set & Cont. & $n$ & $6.3 \pm 0.3$ & $10.3 \pm 0.8$ \\
& 32 & 31.1 & 4 & $6.4 \pm 0.4$ & $13.0 \pm 1.1$ \\
& 26 & 26.7 & 4 & 13.8 & 20.5 \\
& 20 & 20.9 & 1 & 25.9 & 45.8 \\
& 14 & 14.6 & 1 & 0 & 0 \\
2004 & 12 & 11.0 & 1 & & $11.8 \pm 0.3$ \\
& 30 & 30.0 & $4(12)$ & $7.2 \pm 0.3$ & $14.3 \pm 0.4$ \\
& 25 & 24.7 & $8(28)$ & $8.4 \pm 0.3$ & $19.1 \pm 0.8$ \\
& 20 & 20.3 & $5(13)$ & $11.9 \pm 0.5$ & $39.6 \pm 1.8$ \\
& 15 & 15.1 & $4(11)$ & $23.8 \pm 1.4$ & 0 \\
& $12^{b}$ & 14.1 & $1(1)$ & 37.2 & 52.7 \\
& 12 & 11.8 & $2(5)$ & 0 & \\
\hline
\end{tabular}

Time is measured as modal development time in 2001 and as first $10 \%$ (minute duration) in 2004. The number of experimental units, or chambers used to calculate averages, is indicated by $n$. Total subsamples or rearing containers within chambers are indicated by values in parentheses.

${ }^{a}$ Averages include all chamber replications of equal set-chamber temperatures with one exception (see footnote $b$ ).

${ }^{b}$ This set-chamber temperature deviated high enough from rearing-container temperature that development could occur. But because development occurred near the observed minimum threshold, it was separated from containers (and chambers) where development did not occur $\left(<12.2^{\circ} \mathrm{C}\right)$. Including this point with those of similar set-chamber temperatures $\left(12^{\circ} \mathrm{C}\right)$ would be misrepresentative.

noted as ${ }^{\mathrm{e}-\mathrm{p}} \mathrm{ADD}_{\mathrm{x} \text {-int. }}$. When the base temperature reflects a value different from the $\mathrm{x}$-intercept, we define the terminology as $\mathrm{ADD}_{\#}$ or $\mathrm{ADD}_{\mathrm{Tb}}$ where the base temperature $\left(\mathrm{T}_{\mathrm{b}}\right)$ is a number.

\section{Results}

Set-chamber temperatures tended to be higher than rearing container temperatures, although not significantly $(P=0.43)$ (Fig. 1). This deviation resulted in a slope coefficient $<1(0.96)$ and an intercept $>0$.

The nonlinear regression fit to all data points showed the developmental curve under rearing-container temperatures differed from the curve under set-chamber temperatures (Fig. 2A and B). The cor-

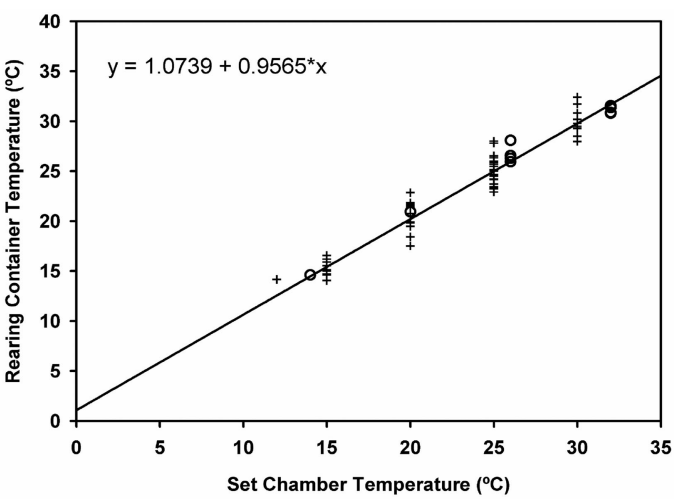

Fig. 1. Deviation in temperature between set chamber temperature and rearing container temperatures for both studies.

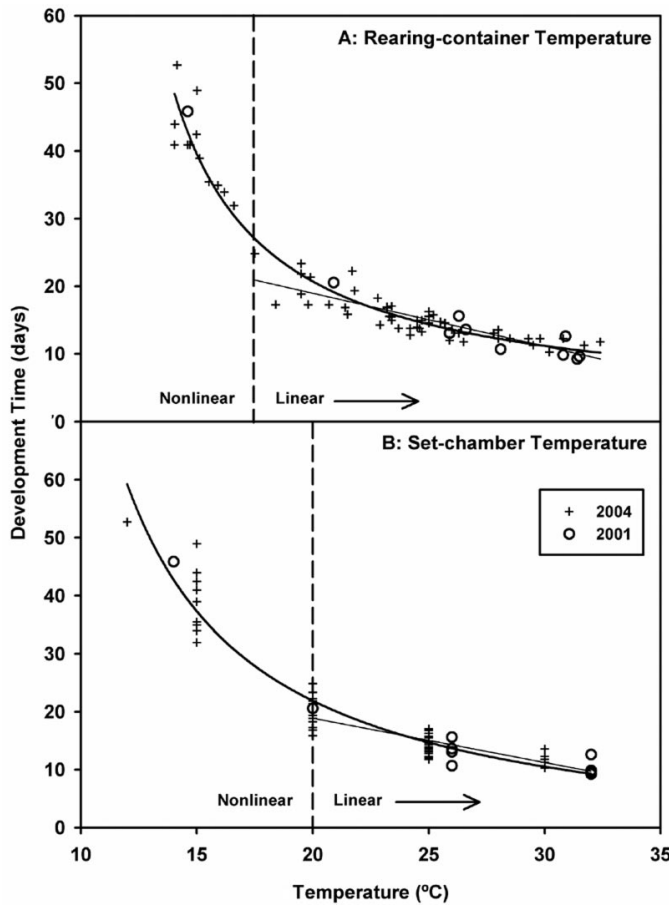

Fig. 2. Nonlinear regression of developmental time from egg to adult for $P$. regina by using rearing-container temperature (A) and set-chamber temperature (B). A $=-17.83+$ $19.41 \mathrm{x} /(\mathrm{x}-9.93), R^{2}=0.95$; and $\mathrm{B}=-65.65+60.43 \mathrm{x} /(\mathrm{x}-$ $6.19), R^{2}=0.92$. The dashed line represents the cutoff to where linearity or, more aptly, approximated linearity becomes statistically nonlinear (as temperatures decrease) based on the methods for the given data set.

relation was higher using rearing-container temperatures $\left(R^{2}=0.95\right)$ versus set-chamber temperatures $\left(R^{2}=0.92\right)$, indicating a slightly better $\mathrm{x}$-axis distribution. Even though rearing-chamber temperatures explain $3 \%$ more of the variation, the difference is not biologically significant.

When using nonlinear regression, variance structure can become skewed if data points are averaged, and especially if the averages represent a different number of points. Consequently, Table 1 represents only averaged data for each different year and commentary on standard errors and confidence intervals is limited to unaveraged data (Fig. 2A and B). From the runs test, we identified where the temperaturedevelopmental time relationship became nonlinear $\left(17.5^{\circ} \mathrm{C}\right)$ for both adult and pupal development. When we generated the $95 \%$ prediction band, one point was removed from the adult developmental time data set (at $25.1^{\circ} \mathrm{C}$ ), whereas three points were removed from the pupal developmental time data set (at 25.1, 25.9, and $28.1^{\circ} \mathrm{C}$ ) (data not shown; see Nabity 2005).

Developmental times did not differ for egg-to-adult emergence $(P=0.13)$ between studies from 2001 and 2004. Similarly, developmental times from egg to pupation did not differ between studies $(P=0.325)$, so data sets were combined for all additional compari- 


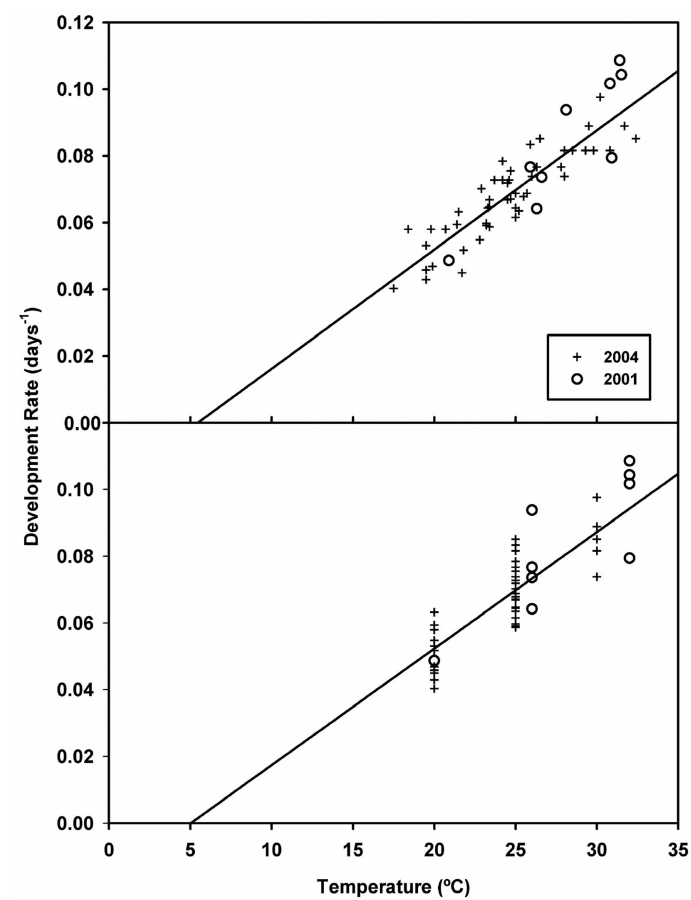

Fig. 3. Linear regression of transformed $\left(\right.$ days $\left.^{-1}\right)$ developmental time from egg to adult $P$. regina by using rearingcontainer (A) and set-chamber (B) temperatures. $\mathrm{A}=$ $0.0036 \mathrm{x}-0.0195, R^{2}=0.79$; and $\mathrm{B}=0.0035 \mathrm{x}-0.0175, R^{2}=$ 0.74 . For $\mathrm{x}$-intercept, $\mathrm{A}=5.4^{\circ} \mathrm{C}$ and $\mathrm{B}=5.0^{\circ} \mathrm{C}$.

sons. Combined developmental rates from egg to pupation, however, were significantly faster than developmental rate from egg to adult emergence $(P=$ 0.001). Comparisons between our measures of developmental time, whether by mode or first $10 \%$, did not differ.

Data points along the linear portion of the nonlinear regression were transformed $\left(\right.$ days $\left.^{-1}\right)$ as is the standard in degree-day analyses (Arnold 1959) to construct a relationship between developmental rate and both rearing-container and set-chamber temperatures (Fig. 3A and B). Regression of set-chamber and rearing-container temperatures against developmental rates generated nearly equal parameters (set temp. slope $=0.00349$, cont. temp. slope $=0.00357$ ), resulting in similar $\mathrm{x}$-intercepts $\left(5.0\right.$ and $5.46^{\circ} \mathrm{C}$, respectively). When we evaluated pupal developmental rate within its corresponding linear data set, we also found similar values between set and rearing-container temperatures (set temp. slope $=0.00582$, x-int. $=5.1^{\circ} \mathrm{C}$; cont. temp.: slope $=0.00574$, $\mathrm{x}$-int. $=4.8^{\circ} \mathrm{C}$ ). The transformation of rate to $\mathrm{ADD}_{\mathrm{x} \text {-int }}$ resulted in similar values for averaged $\mathrm{ADD}_{\mathrm{x} \text {-int }}$ for both adult $\left(281 \mathrm{e}^{\mathrm{e}-\mathrm{a}} \mathrm{ADD}_{5.46}\right)$ and pupal $\left(174{ }^{\mathrm{e}-\mathrm{p}} \mathrm{ADD}_{4.8}\right)$ developmental times compared with the inverse slope $\left(\mathrm{b}^{-1}: 280{ }^{\mathrm{e}-\mathrm{a}} \mathrm{ADD}_{5.46} ; 174\right.$ ${ }^{\mathrm{e}-\mathrm{p}} \mathrm{ADD}_{4.8}$ ) of the regression line through development rate versus temperature (Fig. $4 \mathrm{~A}$ ).

The value of the $x$-intercept depends upon the data being regressed. Therefore, the set versus container

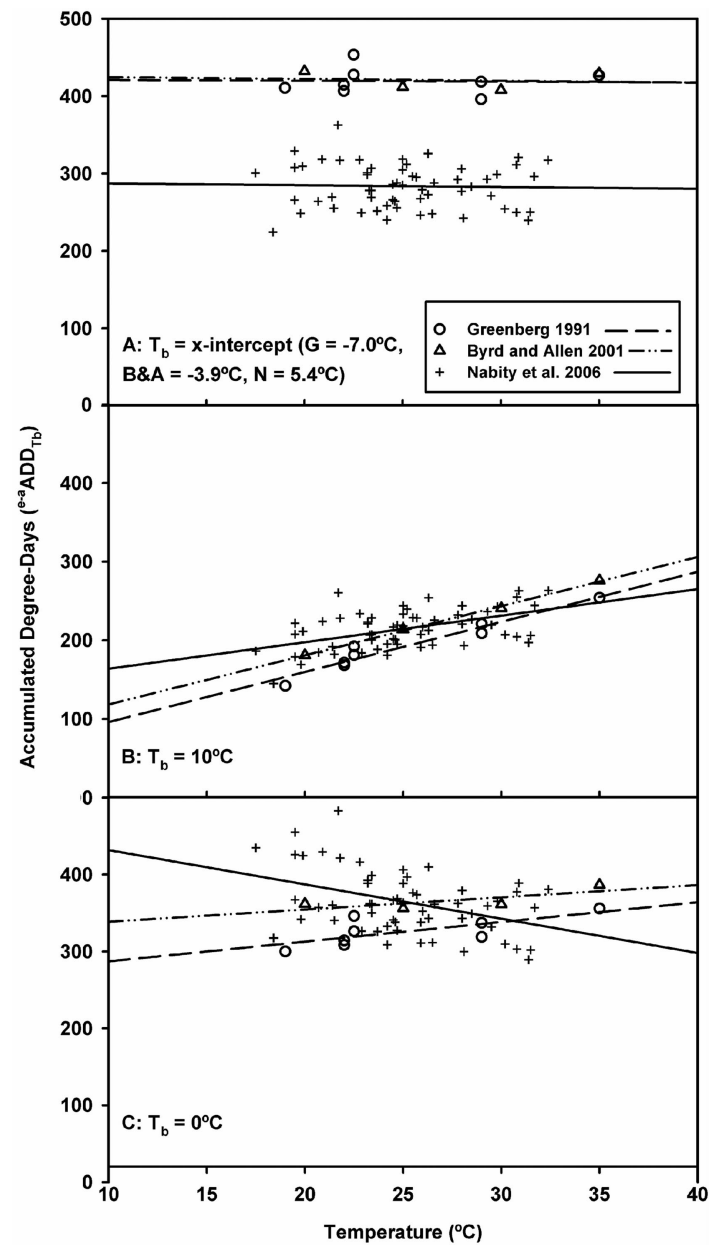

Fig. 4. Accumulated degree-days plotted using the calculated $\mathrm{x}$-intercept (specific to one study's data; Greenberg $=-7.0^{\circ} \mathrm{C}$, Byrd and Allen $=-3.9^{\circ} \mathrm{C}$, and Nabity et al. $=5.4^{\circ} \mathrm{C}$ ) as the base temperature $(\mathrm{A})$, compared with various published base temperatures $10^{\circ} \mathrm{C}(\mathrm{B})$ and $0^{\circ} \mathrm{C}(\mathrm{C})$. As discussed in the text, when the base temperature is above the x-intercept (e.g., $10^{\circ} \mathrm{C}>5.4^{\circ} \mathrm{C}$ for Nabity et al. 2007) the regression slope is positive and ADD values are lower; when the base temperature is below the $\mathrm{x}$-intercept $\left(\right.$ e.g., $0^{\circ} \mathrm{C}<$ $5.4^{\circ} \mathrm{C}$ for Nabity et al. 2006) the regression slope is negative and ADD values are higher.

$x$-intercepts are very different when developmental times are averaged across replications (i.e., all developmental data from chambers set to $12^{\circ} \mathrm{C}$ are averaged to yield one developmental time for that specific temperature). Whether using averages of replicates across equal set-chamber temperatures and regressing with set-chamber temperatures $\left(5.4^{\circ} \mathrm{C}, \mathrm{b}^{-1}=279\right)$, or using the same developmental data and regressing with rearing-container temperatures $\left(7.3^{\circ} \mathrm{C}, \mathrm{b}^{-1}=\right.$ 253), both $x$-intercepts are valid for their respective data sets. This relationship is what creates the differences in base temperatures seen in Table 2 .

Although the base temperature determined by $\mathrm{x}$ intercept must be used in degree-day calculations, 
Table 2. ADD to adult development by using averaged developmental time and selected base temperatures

\begin{tabular}{|c|c|c|c|c|c|c|c|c|c|c|c|c|c|}
\hline \multicolumn{4}{|c|}{ Byrd and Allen $(2001)^{a}$} & \multicolumn{3}{|c|}{ Greenberg (1991) } & \multicolumn{3}{|c|}{$\begin{array}{l}\text { Combined } 2001 \text { and } \\
2004 \text { (set) }\end{array}$} & \multicolumn{4}{|c|}{$\begin{array}{l}\text { Combined } 2001 \text { and } 2004 \text { (rearing- } \\
\text { container) }\end{array}$} \\
\hline Set $\left({ }^{\circ} \mathrm{C}\right) \mathrm{T}_{\mathrm{b}}=$ & $10^{\circ} \mathrm{C}$ & $0^{\circ} \mathrm{C}$ & $\overline{\left(-4.0^{\circ} \mathrm{C}\right)}$ & $10^{\circ} \mathrm{C}$ & $0^{\circ} \mathrm{C}$ & $\overline{\left(-6.8^{\circ} \mathrm{C}\right)}$ & $10^{\circ} \mathrm{C}$ & $0^{\circ} \mathrm{C}$ & $\left(5.4^{\circ} \mathrm{C}\right)^{b}$ & Cont. ${ }^{\circ} \mathrm{C} \mathrm{T}_{\mathrm{b}}=$ & $10^{\circ} \mathrm{C}$ & $0^{\circ} \mathrm{C}$ & $\left(7.3^{\circ} \mathrm{C}\right)^{b}$ \\
\hline $10^{c}$ & 0 & 0 & 0 & & & & & & & $11.0^{c}$ & 0 & 0 & 0 \\
\hline $12^{c d}$ & & & & & & & 105 & 632 & 348 & $14.1^{c}$ & 216 & 743 & 356 \\
\hline $14^{c}$ & & & & & & & 183 & 642 & 394 & $14.6^{c}$ & 211 & 660 & 333 \\
\hline $15^{c}$ & 157 & 470 & 595 & & & & 198 & 594 & 380 & $15.1^{c}$ & 202 & 598 & 307 \\
\hline 19 & & & & 142 & 300 & 407 & & & & & & & \\
\hline 20 & 181 & 362 & 434 & & & & 193 & 387 & 282 & 20.3 & 205 & 398 & 256 \\
\hline $22^{e}$ & & & & 170 & 311 & 409 & & & & & & & \\
\hline $22.5^{e}$ & & & & 187 & 336 & 438 & & & & & & & \\
\hline 25 & 214 & 356 & 413 & & & & 215 & 358 & 280 & 24.8 & 210 & 353 & 248 \\
\hline 26 & & & & & & & 207 & 337 & 267 & 26.7 & 217 & 346 & 251 \\
\hline $29^{e}$ & & & & 215 & 328 & 405 & & & & & & & \\
\hline 30 & 241 & 361 & 409 & & & & 236 & 354 & 290 & 30.0 & 236 & 354 & 267 \\
\hline 32 & & & & & & & 227 & 330 & 274 & 31.1 & 218 & 321 & 245 \\
\hline 35 & 276 & 386 & 431 & 254 & 356 & 425 & & & & & & & \\
\hline 40 & 0 & 0 & 0 & & & & & & & & & & \\
\hline Avg & 228 & 366 & 422 & 194 & 326 & 417 & 216 & 353 & 279 & Avg & 217 & 355 & 254 \\
\hline SD & 40 & 14 & 12 & 43 & 22 & 14 & 17 & 22 & 9 & SD & 12 & 28 & 9 \\
\hline
\end{tabular}

Base temperatures included both absolute and investigator preferred minimums $\left(0\right.$ and $\left.10^{\circ} \mathrm{C}\right)$ and empirically determined $\mathrm{x}$-intercepts (through regression of days ${ }^{-1}$ vs. temperature) from published data. The $\mathrm{x}$-intercept calculated from the temperatures shown is represented by the value in parentheses. Average and standard deviation were calculated using only values within the linear range as determined by the methods.

${ }^{a}$ Development times used to calculate ADD are means from Table 8 in Byrd and Allen (2001).

${ }^{b}$ The x-intercepts calculated on combined 2001 and 2004 data are generated from Table 1 . The difference between $\mathrm{x}$-intercepts in Table 2 and data elsewhere in this article reflects a mathematical artifact from regressing data of similar yet different values. Consequently, $\mathrm{x}$-intercept data here are only valid in the context of comparisons in this table.

${ }^{c}$ Developmental time at this temperature is outside the linear range.

${ }^{d}$ As seen in Table 1, one chamber from 2004 registered a rearing-container temp $\left(14.1^{\circ} \mathrm{C}\right)$ high enough above set-chamber temperature $\left(12^{\circ} \mathrm{C}\right)$ for development to occur $\left(\right.$ at $12^{\circ} \mathrm{C}^{\mathrm{e}-\mathrm{a}} \mathrm{ADD}_{10},{ }^{\mathrm{e}-\mathrm{a}} \mathrm{ADD}_{0}$, and ${ }^{\mathrm{e}-\mathrm{a}} \mathrm{ADD}_{7.6}$ are 74,446 , and 164 , respectively). But because this point is within the nonlinear portion $\left({ }^{a}\right)$, it is not used to figure averages.

${ }^{e}$ Average of published values from Greenberg (1991). All times are average minimum duration from Tables 2,6 , and 7 in Greenberg (1991).

it may not be biologically meaningful (Arnold 1959). P. regina development to adult $\left(\mathrm{x}\right.$-intercept $\left.=5.46^{\circ} \mathrm{C}\right)$ was not observed at or below $14^{\circ} \mathrm{C}$. Hatch occurred at $11^{\circ} \mathrm{C}$ and larval development progressed to pupation at $12.2^{\circ} \mathrm{C}$, although emergence did not occur. We then calculated ${ }^{\mathrm{e}-\mathrm{a}} \mathrm{ADD}_{\mathrm{Tb}}$ for each year of data by using set-chamber temperatures and base temperatures $(0$ and $10^{\circ} \mathrm{C}$ ) found in published data sets from Greenberg (1991) and Byrd and Allen (2001). We also determined ADD by using the $\mathrm{x}$-intercepts calculated from those studies and from our own averaged data (Table 2). Finally, we combined our two studies to show ADD calculated from rearing-container temperatures by using different base temperatures. Because we averaged our data and then calculated the $x$-intercept, our $\mathrm{x}$-intercept base temperature $\left(7.3^{\circ} \mathrm{C}\right)$ is higher than what was calculated using unaveraged data $\left(5\right.$ or $\left.46^{\circ} \mathrm{C}\right)$. Also, average and SD values are generated from only values within the linear portion of the temperature-developmental time relationship. The resulting linear regressions using investigator preferred values $\left(10\right.$ or $\left.0^{\circ} \mathrm{C}\right)$ yielded lines with positive slopes (Fig. 4 and 4C), whereas the same ${ }^{\mathrm{e}-\mathrm{a}} \mathrm{ADD}$ calculated using the $\mathrm{x}$-intercept as the temperature base resulted in a horizontal regression line (Fig. 4A). The theoretical relationship between $\mathrm{ADD}_{\text {x-int }}$ and temperature is a horizontal line with the thermal constant (or inverse slope) equal to the y-axis intercept (Arnold 1959).

We calculated regression parameters (x-intercept, $\mathrm{b}^{-1}$, and ADD) of current published data sets on
$P$. regina to compare $\mathrm{x}$-intercepts, replication, and how differences in developmental data alter estimations of the PMI (Table 3). Given a temperature of $23^{\circ} \mathrm{C}$, our data suggest development from egg to adult in $16.1 \mathrm{~d}$, similar in agreement to Byrd and Allen (2001) (15.6) and Greenberg (1991) (14.0).

\section{Discussion}

Using linear regression analysis, a line can be fitted to approximate a constant growth rate across median temperatures. Although this line yields an extrapolated developmental minimum, the actual developmental minimum occurs at a higher temperature because of curvilinear responses at low temperatures. We observed egg hatch at $11.7^{\circ} \mathrm{C}$, cessation of larval development at and below $12^{\circ} \mathrm{C}$ (larvae died), and at a temperature of $12.2^{\circ} \mathrm{C}$ larvae pupated but did not emerge. We observed complete egg-to-adult development at $14^{\circ} \mathrm{C}$; therefore, our best estimate of the biological developmental minimum is $14^{\circ} \mathrm{C}$. If a definitive minimum threshold exists (and a single threshold may not apply, given possible genetic variation among populations), our data indicate this value would lie between 12.2 and $14^{\circ} \mathrm{C}$. Thus, when a biologically meaningful lower developmental threshold is needed, $14^{\circ} \mathrm{C}$ should be used rather than $10^{\circ} \mathrm{C}$ as has been assumed in other studies (Kamal 1958, Greenberg 1991, Byrd and Allen 2001). Note that the biological developmental threshold is different from the minimum threshold used for degree-day cal- 
Table 3. Experimental parameters of several studies on $P$. regina

\begin{tabular}{|c|c|c|c|c|c|c|c|c|c|}
\hline Study & Oviposition to & $\begin{array}{l}\text { No. } \\
\text { temp }\end{array}$ & $\begin{array}{l}\text { Temp range } \\
\left({ }^{\circ} \mathrm{C}\right)\end{array}$ & $\begin{array}{l}\text { Developmental } \\
\text { min. by x-intercept }\end{array}$ & $\begin{array}{l}\mathrm{ADD} \\
\left(\mathrm{b}^{-1}\right)\end{array}$ & $\begin{array}{l}\text { ADD } \\
(\text { mean })\end{array}$ & $\begin{array}{l}\mathrm{ADD} \\
(\mathrm{SE})\end{array}$ & $\begin{array}{c}\text { Time to reach } \\
\text { stage at } 23^{\circ} \mathrm{C}(\mathrm{d})\end{array}$ & $\mathrm{SE}(\mathrm{d})$ \\
\hline \multirow[t]{3}{*}{ Greenberg (1991) } & Egg eclosion & 2 & 22 and 29 & -41.0 & 52.5 & 53 & 0.0 & 0.8 & 0.0 \\
\hline & Pupation & 2 & 22 and 29 & -9.50 & 289 & 289 & 0.0 & 8.9 & 0.0 \\
\hline & Adult emergence & 8 & $19-35$ & -6.80 & 416 & 417 & 6.1 & 14.0 & 0.2 \\
\hline \multirow{3}{*}{ Byrd and Allen (2001) } & Egg eclosion & 4 & $15-35$ & -23.6 & 39 & 39 & 0.1 & 0.8 & 0.0 \\
\hline & Pupation & 4 & $15-35$ & -0.06 & 222 & 223 & 12.3 & 9.6 & 0.5 \\
\hline & Adult emergence & 4 & $15-35$ & -4.00 & 421 & 422 & 6.2 & 15.6 & 0.2 \\
\hline \multirow[t]{3}{*}{ Anderson (2000) } & Egg eclosion & 2 & 16.1 and 23 & 9.20 & 12 & 12 & - & 0.9 & - \\
\hline & Pupation & 2 & 16.1 and 23 & 9.38 & 123 & 123 & - & 9.1 & - \\
\hline & Adult emergence & 2 & 16.1 and 23 & 8.76 & 219 & 219 & - & 15.1 & - \\
\hline Nabity et al. (2006) & Pupation & 58 & $17.5-32.4$ & 4.76 & 174 & 174 & 3.0 & 9.6 & 0.2 \\
\hline This study & Adult emergence & 61 & $17.5-32.4$ & 5.46 & 280 & 281 & 3.6 & 16.1 & 0.2 \\
\hline
\end{tabular}

The $\mathrm{x}$-intercepts were determined using the range of linear data (as determined by the methods of this study) and subsequent ADD were calculated using $\mathrm{x}$-intercepts as the base temperatures. Data were taken from published values (excepting data from this study). In one instance where only two temperatures were available (Anderson 2000), degree-day assumptions were not met (ADD were not independent of temperature).

culations that must be the $\mathrm{x}$-intercept threshold to meet assumptions underlying the degree-day method (Arnold 1959).

Grassberger and Reiter (2002b) noted a similar response in Protophormia terraenovae (RobineauDesvoidy); the regressed larval developmental minimum $\left(8.9^{\circ} \mathrm{C}\right)$ was lower than the pupal $\left(9.8^{\circ} \mathrm{C}\right)$ minimum. However, their regression included a low temperature point $\left(15^{\circ} \mathrm{C}\right)$ from beyond the linear portion of the temperature-developmental time relationship as defined by the methods in this article. By not including this data point and comparing developmental rates as presented, we see significant differences between egg developmental rates and both pupal and adult developmental rates $(P<0.01)$. Although we used averaged temperature data, developmental rate from egg to pupation also tended to be different from developmental rate from egg to adult $(P=0.11)$. Probably, an analysis of the original data set would generate similar results if not at a lower level of significance (using the raw, unaveraged data). Thus, each stage of development for $\operatorname{Pr}$. terraenovae and $P$. regina has a unique minimum threshold and developmental rate. This phenomenon is common among other insects (e.g., Poston et al. 1977, Fantinou et al. 2003) and likely occurs among all flies of forensic importance.

The significance of an accurate developmental minimum is great, because it is the basis for degree-day calculations, which in turn directly affect the estimate of the PMI. Previous studies on P. regina used a variety of developmental minimums to determine ADD. Greenberg (1991) and Anderson (2000) used $0^{\circ} \mathrm{C}$, whereas Byrd and Allen (2001) used an observed value of $10.0^{\circ} \mathrm{C}$ to calculate thermal constants. Not surprisingly, the degree-day values generated were not constant, and linear regression of the final temperature-ADD relationship showed a nonzero slope, indicating an invalid degree-day model. When $\mathrm{T}_{\mathrm{b}}$ used for degree-day calculations is any value other than the $\mathrm{x}$-intercept, the resulting trend in degree-days will have an increasing or decreasing slope depending on whether $T_{b}$ is greater or less than the $\mathrm{x}$-intercept.
Use of inappropriate minimum thresholds invalidates the basic assumption of linearity in degree-day models (i.e., the developmental rate is not constant across temperature). For example, when values higher than the $\mathrm{x}$-intercept are used, the ADD-temperature relationship has a positive slope, implying fewer ADD are needed for development than is actually the case. Likewise, when values lower than the $\mathrm{x}$-intercept are used, the ADD-temperature relationship has a negative slope, implying more ADD are needed than the true value. Thus, using observed minimum thresholds $\left(14^{\circ} \mathrm{C}\right.$ as in this study) or investigator selected temperatures $\left(0\right.$ or $10^{\circ} \mathrm{C}$ as in other studies) for calculations results in underestimating or overestimating actual degree-days, which, correspondingly, transfers into the estimates of PMI. Unless specified and for comparative purposes only, the base temperature for degree-day calculations must be derived from the $\mathrm{x}$ intercept method to avoid adding bias to final ADD tallies.

What if the $\mathrm{x}$-intercept is lower than the observed minimum threshold (as in this study) or a negative value (e.g., Greenberg 1991, Byrd and Allen 2001)? The $\mathrm{x}$-intercept has no biological meaning but merely serves as the parameter facilitating the linear transformation of developmental rate versus temperature into ADD versus temperature (Arnold 1959). Simply, multiplying developmental time by an augmented temperature (in this case subtracting a constant is a linear transformation as opposed to the inverse time transformation which is nonlinear) rotates the graph of developmental rate until it is horizontal and with increased (scaled) y-axis values. Because this is a linear heat unit system, values outside the linear range do not satisfy the transformations, which becomes problematic when trying to estimate development under low temperatures that fall outside the linear range. Although according to the model, development occurs until the base temperature is reached, observation and common sense tells us that development ceases at least below $0^{\circ} \mathrm{C}$ if not at low temperatures (e.g., $<6^{\circ} \mathrm{C}$ ). Therefore, when calculating ADD by using temperatures outside the linear range, investi- 
gators must use caution; or rather include large degrees of variability until reliable curvilinear models are developed on data sets spanning the entire temperature range.

How does the minimum threshold alter the PMI? The PMI represents the time between when the insects (and body) were sampled (discovered) and when the insects began their development (shortly after death). Hence, the PMI calculated from ADD represents the shortest time frame possible because intrinsic and extrinsic factors only slow, rather than increase, developmental rate. Subsequently variation is assumed into the final PMI and adjusted for scene context (e.g., weather phenomena and wrapped body). This is why PMI from insect development must be considered an estimate and not an absolute time frame. By incorrectly calculating ADD in violation of the model assumptions, bias is introduced into the estimate of the initial PMI based on ADD. Table 3 illustrates this point. Although developmental data from Anderson (2000) are similar in duration to other data on $P$. regina, using only two points to establish a graphical relationship (whether time, time ${ }^{-1}$, or ADD versus temperature) may introduce bias, especially when one of those points is in the curvilinear range for the species as $16.1^{\circ} \mathrm{C}$ is for $P$. regina.

Table 3 illustrates how testing a broad range of temperatures is essential in developing a more accurate model of insect development. For example, although the calculated developmental minima (by $\mathrm{x}$ intercept) and ADD are different between Byrd and Allen (2001) and our study, the application of both models in a development prediction (growth at a constant $23^{\circ} \mathrm{C}$ ) shows developmental predictions differing only by half a day for egg-to-adult development. Table 3 also illustrates that the longer the developmental period, the greater the degree of variation. Undoubtedly, these differences in developmental predictions would be greater under cyclic, field temperatures, given the greater variation associated with field temperature measurements and insect development. Because experimental procedures are so different, comparisons of predicted times of development seem the most appropriate and useful method of assessing the validity of different models.

The comparisons in Table 3 also imply that differences between existing models (experimental determinations of development) lead to estimates differing in over $2 \mathrm{~d}$. Fortunately, the close agreement in predictions from more robust data sets indicates that variation among models should probably be on the order of no $>0.5 \mathrm{~d}$, and probably much less for periods shorter than egg-to-adult development. Unfortunately, until those robust data sets are available for all forensically important species, the validity of PMI estimates from existing data is uncertain.

Greenberg (1991) and Grassberger and Reiter (2001) suggest geographic variation may lead to differences in developmental times and thus developmental minimums. In a related species, Grassberger and Reiter (2002b) found Pr. terraenovae has different minimum thresholds for similar developmental stages across zoogeographic regions as calculated through $\mathrm{x}$-intercepts regression (compared with Marchenko 2001). Although the same difference is shown for $P$. regina in this study, Grassberger and Reiter relied on extrapolation rather than direct observation, used data from outside the range where linearity holds, and generated data under manual temperature checks (twice daily). These checks may have provided only a snapshot of the growth chamber function and how it affected larval development. Based on the information presented in this study, and from the other regional studies on $P$. regina (Kamal 1958; from Washington, Greenberg 1991; from Illinois, Byrd and Allen 2001; from U.S. southeast), overall developmental rate of specimens from different geographic areas seems variable within species, and because of methodology. If we plot temperature versus developmental time for P. regina for all studies, all data points fall along a similar curve, regardless of differences in experimental design. Thus, although there may be variation within the species regarding developmental rate between stages, geography does not seem to alter rates along, at least, the linear portion of the developmental curve. Where geography may play a role in altering developmental time is along the curvilinear portions of the relationship or the real developmental minimum where physiological limitations may be influenced by environment. Future studies should seek to verify this hypothesis.

The lack of statistical differences between rearingcontainer and set-chamber temperatures is probably because of deviations occurring above and below set temperatures and the high correlation of the data (both set-chamber and rearing-chamber temperature use the same developmental data). In our work, we used 16 different chambers across experiments; however, if fewer chambers were used the likelihood of unidirectional bias in temperature would have been greatly increased. Also, if the methods used to identify curvilinearity in the temperature-developmental time relationship were used on set-chamber rather than rearing-container temperatures, the resulting linear regression would be based upon developmental times wrongly associated with higher temperatures within the true curvilinear spectrum for the species.

Rearing-container temperatures showed stronger correlation than set-chamber temperatures to developmental time. This resulted in better $\mathrm{x}$-axis distribution, more indicative of the real curvilinear relationship. Also, because most forensic literature development studies do not replicate between chambers, variation in temperature data are not random, but biased by the chamber. Because we measured the temperature experienced by developing larvae within the chamber and across several chambers, our temperature-developmental time relationship more accurately represents the true relationship. Using set-chamber temperatures would generate the wrong relationship between temperature and developmental time. The resulting data transformation (time ${ }^{-1}$ ) would then include inappropriate data potentially biasing the regression parameters (and calculated 
ADD). When conducting any controlled temperature experiments, we know variation in temperatures occurs between chambers (when more than one chamber are used for a study) and within chambers. However, this error is not discussed in the literature surrounding forensic entomology or degree-day analyses, which inherently depend upon controlled temperatures.

All these sources of variation merge within the final ADD model presented for $P$. regina. Our final model (Fig. 4A) showed ${ }^{\mathrm{e}-\mathrm{a}} \mathrm{ADD} \mathrm{D}_{\mathrm{x} \text {-int }}$ versus temperature for all tested data points (from this study) and other data on P. regina (Greenberg 1991, Byrd and Allen 2001). This regression line should be horizontal across median temperatures if physiological time is constant across temperature. When the improper base temperatures are used (Fig. 4B and C), the slope coefficient becomes nonzero, indicating a violation in model assumptions. Variance of data from the regression line is probably a result of intraspecific variation that may depend upon physiological aspects such as nutrition, hormonal regulation, thermoregulation, or stagespecific development (Higley et al. 1986, Higley and Haskell 2001). Variance also may result from inadequate characterization of the true experienced temperature or approximations/assumption in laboratory estimates of development (Higley et al. 1986). In other forensic studies (Byrd 1996, 1997, 1998), variability in thermal constants occur as well, within degree-hour temperature models when calculated under the proper assumptions.

Finally, by taking raw (unaveraged) data through the transformation process associated with calculating development rates and ADD, the final ADD model accurately depicts variability in development. From this variability, standard errors or confidence intervals can be generated, thereby giving the initial estimate of the PMI an increased degree of accuracy. By using averaged data, no assessment of the variability can be made because the original variance structure is skewed through the nonlinear transformation. Other studies published on averaged data are limited in this fashion, signaling a need for additional developmental studies on forensically important fly species, or publication access to original raw data sets.

It is this estimation and application of errors in forensic sciences that is purported as the coming "paradigm shift" (Saks and Koehler 2005). Our results here strongly indicate the error in PMI estimates from degree-days is greater than has been previously acknowledged. Specifically, 1) experimental error associated with temperature measurement within chamber is a greater issue than error from pseudorandomization and pseudoreplication, per se; 2 ) use of minimum or modal development has no significance in final estimates, as also seen by Byrd and Allen (2001) and Huntington (2005); and 3) use of an improper minimum developmental threshold (any value other than the x-intercept from a specific set of development data) both invalidates degree-day assumptions and leads to the largest errors in estimates of insect development.
Data here provide developmental minima and degree-day accumulations for oviposition to pupation and oviposition to adult emergence. Additional experimentation is needed for degree-day requirements for larval stage and behavioral transitions (mature larval wandering before pupation).

To prevent future confusion regarding developmental studies on insects, but specifically on forensically important insects where data are used to determine PMIs for legal use, we recommend 1) collecting developmental data across the entire temperature spectrum; 2) disclosing all data for use in nonlinear regression analyses; 3) investigating curvilinear approaches for degree-day calculations, especially for the nonlinear portions of the temperature-developmental time relationship; 4) quantifying sources of variation whether in developmental time, experimental design, or regression analyses; and 5) limiting use of degree-days only to temperatures within the linear portion of the temperature-developmental time relationship.

Through a thorough examination of the development of forensically important fly species, we can increase the practical applicability and accuracy of the time frames used in litigative processes. Until we address these issues of variability, unreported data, and adhering to proper assumptions built into modeling and interpretative processes, estimates of the PMI may not be accurate.

\section{Acknowledgments}

We thank S. M. Louda and S. M. Spomer for constructive discussions and editorial remarks, and all who helped monitor fly development and colonies, especially T. R. Brosius, L. D. Franzen, A. Gutsche, T. E. Huntington, and S. E. Svehla. This work was supported by the Nebraska Agricultural Experiment Station (Projects NEB-17-078 and NEB-17-080) and by awards to P.D.N. from the University of Nebraska Pepsi Endowment and Program of Excellence Funds for Undergraduate and Creative Activities and Research Experiences and from an Undergraduate Honors Grant from the Agricultural Research Division, UN-L. This is paper 15101 of the journal series of the University of Nebraska Agricultural Research Division.

\section{References Cited}

Anderson, G. S. 2000. Minimum and maximum development rate of some forensically important Calliphoridae (Diptera). J. Forensic Sci. 45: 824-832.

Arnold, C. Y. 1959. The determination and significance of the base temperature in a linear heat unit system. Proc. Am. Soc. Hortic. Sci. 74: 430-445.

Byrd, J. H., and J. C. Allen. 2001. The development of the black blow fly, Phormia regina (Meigen). Forensic Sci. Int. 120: 79-88.

Byrd, J. H., and J. F. Butler. 1996. Effects of temperature on Cochliomyia macellaria (Diptera: Calliphoridae) development. J. Med. Entomol. 33: 901-905.

Byrd, J. H., and J. F. Butler. 1997. Effects of temperature on Sarcophaga haemorrhoidalis (Diptera: Sarcophagidae) development. J. Med. Entomol. 34: 694-698. 
Byrd, J. H., and J. F. Butler. 1998. Effects of temperature on Chrysomya rufifacies (Diptera: Calliphoridae) development. J. Med. Entomol. 35: 353-358.

Clarkson, C. A., N. R. Hobischak, and G. S. Anderson. 2004. A comparison of the development rate of Protophormia terraenovae (Robineau-Desvoidy) raised under constant and fluctuating temperature regimes. Can. Soc. Forensic Sci. 37: 95-101.

Fantinou, A. A., D. Ch. Perdikis, and C. S. Chatzoglou. 2003. Development of immature stages of Sesamia nonagrioides (Lepidoptera: Noctuidae) under alternating and constant temperatures. Environ. Entomol. 32: 1337-1342.

Goff, M. L., A. I. Omori, and J. R. Goodbrod. 1989. Effect of cocaine in tissues on the development rates of Boettcherisca peregrina (Diptera: Sarcophagidae). J. Med. Entomol. 26: 91-93.

Grassberger, M., and C. Reiter. 2001. Effect of temperature on Lucilia sericata (Diptera: Calliphoridae) development with special reference to the isomegalen- and isomorphen-diagram. Forensic Sci. Int. 120: 32-36.

Grassberger, M., and C. Reiter. 2002a. Effect of temperature on development of Liopygia (=Sarcophaga) argyrstoma (Robineau-Desvoidy) (Diptera: Sarcophagidae) and its forensic implications. J. Forensic Sci. 47: 1-5.

Grassberger, M., and C. Reiter. 2002b. Effect of temperature on development of the forensically important Holarctic blow fly Protophormia terraenovae (Robineau-Desvoidy) (Diptera: Calliphoridae). Forensic Sci. Int 128: $177-182$.

Grassberger, M., E. Freidrich, and C. Reiter. 2003. The blowfly Chrysomya albiceps (Wiedemann) (Diptera: Calliphoridae) as a new forensic indicator in Central Europe. Int. J. Leg. Med. 117: 75-81.

Greenberg, B. 1991. Flies as forensic indicators. J. Med. Entomol. 28: 565-577.

Hall, D. G. 1948. The blowflies of North America. Thomas Say Foundation, Baltimore, MD.

Hedges, L. V., and L. Olkin 1985. Statistical methods for meta-analysis. Academic, Orlando, FL.

Higley, L. G., and N. H. Haskell. 2001. Insect development and forensic entomology, pp. 287-302. In J. H. Byrd and
J. L. Castner [eds.], Forensic entomology: the utility of arthropods in legal investigations. CRC, Boca Raton, FL.

Higley, L. G., L. P. Pedigo, and K. R. Ostlie. 1986. DEGDAY: A program for calculating degree days, and assumptions behind the degree day approach. Environ. Entomol. 15: $999-1016$.

Huntington, T. E. 2005. Temperature-dependent development of blow flies of forensic importance and the effects on the estimation of the postmortem interval. M.S. thesis, University of Nebraska, Lincoln, NE.

Hurlbert, S. H. 1984. Pseudoreplication and the design of ecological field experiments. Ecol. Monogr. 54: 187-211.

Kamal, A. S. 1958. Comparative study of thirteen species of sarcosaprophagous Calliphoridae and Sarcophagidae (Diptera). I. Bionomics. Ann. Entomol. Soc. Am. 51: 261270.

Kaufmann, O. 1932. Einige bemerkuungen uber den einfluss von temperatureschwankungen auf die entwicklungsdauer und streuung bei insekten und seine graphische darstellung durch kettelinie und hyperbel. Z. Morph. Okol. Tiere 25: 353-361.

Marchenko, M. I. 2001. Medicolegal relevance of cadaver entomofauna for the determination of the time since death. Forensic Sci. Int. 120: 89-109.

Nabity, P. D. 2005. A comparison of abiotic and biotic factors on the physiological ecology of plants and insects. M.S. thesis, University of Nebraska, Lincoln, NE.

Nabity, P. D., L. G. Higley, and T. M. Heng-Moss. 2007. Light-induced variability in the development of the forensically important blow fly, Phormia regina (Meigen) (Diptera: Calliphoridae). J. Med. Entomol. (in press).

Poston, F. L., R. B. Hammond, and L. P. Pedigo. 1977. Growth and development of the painted lady on soybeans (Lepidoptera: Nymphalidae). J. Kans. Entomol. Soc. 50: 31-36.

Saks, M. J., and J. J. Koehler. 2005. The coming paradigm shift in forensic identification science. Science (Wash., D.C.) 309: $892-895$

SAS Institute. 2002. PROC user's manual, version 9.1. SAS Institute, Cary, NC.

Received 12 May 2006; accepted 4 August 2006 